\title{
Letter to the editor regarding "A randomized controlled trial: comparing extracorporeal shock wave therapy versus local corticosteroid injection for the treatment of carpal tunnel syndrome"
}

\author{
Cong-Xian Chen ${ }^{1} \cdot$ Zeng Zeng $^{1}$ (D)
}

Received: 20 August 2020 / Accepted: 15 September 2020 / Published online: 22 September 2020

(c) Springer Science+Business Media, LLC, part of Springer Nature 2020

To the editor,

We read with great interest the article of Xu et al. [1] titled "A randomized controlled trial: comparing extracorporeal shock wave therapy versus local corticosteroid injection for the treatment of carpal tunnel syndrome" in a recent issue of the journal. I have some queries on the article.

In statistical analysis part, Xu et al. used paired-sample $\mathrm{t}$ tests to compare the outcomes of each follow-up and pretreatment visit between the two groups [1]. It is well known that paired-samples $t$ test can be used only when both groups have the same number of samples [2]. However, on results part, 55 patients were enrolled and randomly divided into two groups (30 in the ESWT group and 25 in the LCI group). So the number of samples were not same. This is an obvious error.

Another query is, in Xu's study, left or right hands carpal tunnel syndrome are not indicated [1], we wonder whether non-dominant hand will cause better prognosis or not, cause in Tang's study the patients with severe CTS achieved a complete resolution in the non-dominant hand in a shorter time compared with the dominant one, and the symptoms diminished faster in the non-dominant hand after the release of CTS in patients with severe CTS [3].

Yours Sincerely.

\section{Compliance with ethical standards}

Conflict of interest The author declares no conflict of interest.

Ethical approval This article does not contain any studies with animals performed by any of the authors.

\section{References}

1. Xu DL, Ma WH, Jiang WY, et al. A randomized controlled trial: comparing extracorporeal shock wave therapy versus local corticosteroid injection for the treatment of carpal tunnel syndrome. Int Orthop. 2020;44(1):141-6.

2. Derrick B, Toher D, Russ B, et al. Test statistics for the comparison of means for two samples that include both paired and independent observations. J Mod Appl Stat Methods. 2017;16(1):137-57.

3. Tang QY, Lai WH, Tay SC. The effect of hand dominance on patient-reported outcomes of carpal tunnel release in patients with bilateral carpal tunnel syndrome. J Hand Surg (Asian-Pacific Vol). 2017;22(3):303-8.

Publisher's Note Springer Nature remains neutral with regard to jurisdictional claims in published maps and institutional affiliations.
Zeng Zeng

lois1@163.com

1 Department of Ultrasound, Zhejiang Provincial People's

Hospital, Hangzhou, Zhejiang, China 